\title{
乌s \\ Cryogenic test of a proof-of-principle superconducting rf-dipole deflecting and crabbing cavity
}

\author{
S. U. De Silva* and J.R. Delayen ${ }^{\dagger}$ \\ Center for Accelerator Science, Department of Physics, Old Dominion University, Norfolk, Virginia 23529, USA, \\ and Accelerator Division, Thomas Jefferson National Accelerator Facility, Newport News, Virginia 23606, USA
}

(Received 26 June 2013; published 16 August 2013)

\begin{abstract}
Recent applications in need of compact low-frequency deflecting and crabbing cavities have initiated the design and development of new superconducting structures operating at high gradients with low losses. Previously, $\mathrm{TM}_{110^{-}}$-type deflecting and crabbing cavities were developed and have also been operated successfully. However, these geometries are not favorable designs for low operating frequencies. The superconducting rf-dipole cavity is the first compact deflecting and crabbing geometry that has demonstrated high gradients and high shunt impedance. Since the fundamental operating mode is the lowest mode and is widely separated from the nearest higher order mode, the rf-dipole design is an attractive geometry for effective damping of the higher order modes in high current applications. A $400 \mathrm{MHz}$ rf-dipole cavity was designed, fabricated, and tested as a proof-of-principle cavity. The cavity achieved high operating gradients, and the multipacting levels were easily processed and did not reoccur.
\end{abstract}

DOI: 10.1103/PhysRevSTAB.16.082001

PACS numbers: 29.27.Ac, 41.85.Ar, 41.85.Ct

\section{INTRODUCTION}

The early application of deflecting/crabbing cavities was in rf deflecting systems designed to separate high energy particle beams [1]. A deflecting cavity system separates a single beam into multiple beams by providing a transverse momentum at the center of each bunch, displacing the bunch off axis at an angle. The corresponding rf phase at which the transverse force is applied is determined by the number of separated beams. The first experimental attempt in designing deflecting cavities was the $2.856 \mathrm{GHz}$ rectangular deflecting cavity that successfully deflected a $150 \mathrm{MeV}$ electron beam at the Mark III linear electron accelerator at Stanford University in 1960 [1]. Following that success, in the early 1960's concurrent work was pursued at CERN [2], SLAC [3], and BNL [4], leading to more advanced designs such as the multicell $\mathrm{TM}_{11}$-type disk loaded waveguide structure [5].

The first superconducting rf deflecting structure was designed at KfK Karlsruhe in collaboration with CERN [6]. The 104-cell standing wave rf particle separator cavity installed at CERN in 1977 was capable of delivering a deflection in the vertical plane. The deflecting cavity is currently at IHEP. Since then several superconducting and room temperature deflecting structures have been designed and operated $[7,8]$.

The number of particles colliding at the interaction point is one of the factors contributing to luminosity in a particle

\footnotetext{
*pdesilva@odu.edu; sdesilva@jlab.org
}

†jdelayen@odu.edu; delayen@jlab.org

Published by the American Physical Society under the terms of the Creative Commons Attribution 3.0 License. Further distribution of this work must maintain attribution to the author(s) and the published article's title, journal citation, and DOI. collider, where well-overlapped bunches enable the collision of the maximum number of particles in each bunch. The crab crossing concept proposed by Palmer [9] suggests using a crabbing cavity system to increase the luminosity in linacs, and also in collider rings [10]; a crabbing system would allow head-on collision of bunches at the interaction point or provide luminosity leveling. The transverse momentum imparted in opposite direction to the head and tail of each bunch rotates them allowing the overlapped collision. The crabbing cavities are placed on the beam line at zero crossing and operate with a $\pm 90^{\circ}$ synchronous $\mathrm{rf}$ phase. A set of crabbing cavities is used after the interaction point to compensate the oscillation which otherwise may lead to beam instabilities. The first crabbing cavity system was developed and installed in 2007 at KEK $[11,12]$ for the KEKB electron-positron collider. The crabbing cavity operating in $\mathrm{TM}_{110}$-like mode at $509 \mathrm{MHz}$ was the only crabbing cavity system that has been in operation in a particle collider. The functional specifications and dimensional constraints in recent applications, such as the crabbing cavity requirements in the LHC high luminosity upgrade [13], require compact superconducting deflecting and crabbing cavities. Some of those designs are the SLAC half-wave spoke resonator crabbing cavity [14], the parallelbar cavity [15], the Lancaster University-Cockroft Institute 4-rod cavity [16], the KEK Kota Cavity [17], and the BNL quarter-wave cavity [18]. The new compact rf structures operate in TEM-like or TE-like modes [17,19] where the rf-dipole cavity is one of them.

The superconducting rf-dipole geometry, shown in Fig. 1, is a compact deflecting and crabbing design with attractive rf properties. The design has evolved from the parallel-bar design with rectangular outer conductor and cylindrical loading elements operating in a TEM-like mode [15] into a cylindrical design with trapezoidal-shaped 


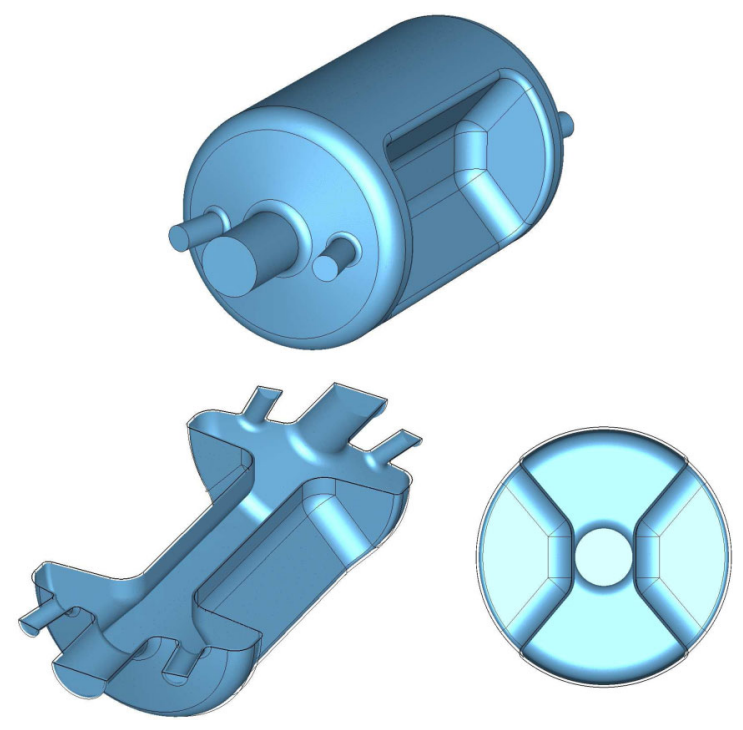

FIG. 1. Radio-frequency-dipole geometry and cross section.

loading elements [20]. The cavity was designed to maximize the net deflection with low peak surface fields and minimize the power dissipation on the surface with high shunt impedance [21]. The trapezoidal-shaped loading elements were optimized to reduce both peak surface electric and magnetic fields and maximize the transverse electric field [20]. The design optimization was done using CST MICROWAVE STUDIO [22].

The cavity operates in a $\mathrm{TE}_{11}$-like mode, in which the main contribution to the transverse momentum is from the on-axis transverse electric field as shown in Fig. 2. As stated in the Panofsky-Wenzel theorem [23,24], deflecting and crabbing cavities cannot operate in a pure TE mode since the transverse momenta produced by the transverse electric and magnetic fields are equal and opposite. Alternatively, the operating mode of the rf-dipole cavity can be visualized as two $\lambda / 2$ resonators that have evolved into two opposite $\lambda / 4$ resonators [20]. The electromagnetic field profile and surface fields of the rf-dipole cavity are shown in Figs. 2 and 3. In the rf-dipole geometry the fundamental operating mode is the lowest mode and there are no lower order modes. The frequency of the first higher order mode is approximately 1.5 the frequency of the

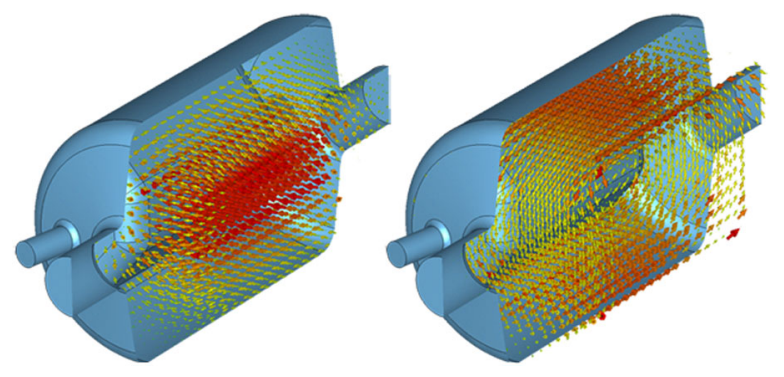

FIG. 2. Electric (left) and magnetic (right) field profile in the rf-dipole cavity.

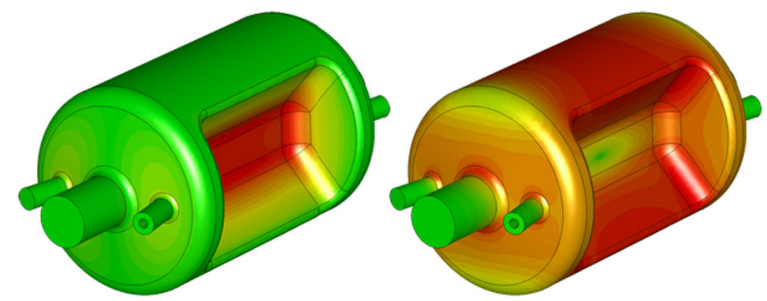

FIG. 3. Surface electric (left) and magnetic (right) fields in the rf-dipole cavity.

fundamental mode, with a widely separated higher order mode spectrum [25]. We have designed and developed a $400 \mathrm{MHz}$ superconducting proof-of-principle rf-dipole cavity whose properties are shown in Table I, and we present here the results of the cryogenic tests of that cavity.

\section{FABRICATION, PROCESSING, AND PREPARATION}

The $400 \mathrm{MHz}$ rf-dipole cavity was manufactured by and as part of a collaboration with Niowave Inc. [26]. The proof-of-principle rf-dipole cavity was designed and fabricated with four identical side ports, as shown in Figs. 1 and 4 , in order to prevent an on-axis longitudinal electric field component by maintaining the symmetry, and to ease the processing and cleaning of the cavity. The location of the ports was chosen to provide optimal coupling to the transverse electric field on the midplane.

The diameter of the beam ports of the cavity is $84 \mathrm{~mm}$, which is an LHC requirement [27], and the diameter of the four side ports is $36 \mathrm{~mm}$. Two of the side ports were used for the input and output couplers, the others could be used

TABLE I. Properties of the rf-dipole geometry shown in Figs. 1 and 4.

\begin{tabular}{lcc}
\hline \hline Parameter & Value & Units \\
\hline Frequency & 400 & $\mathrm{MHz}$ \\
Frequency of nearest mode & 590 & $\mathrm{MHz}$ \\
$\lambda / 2$ of $\pi$ mode & 374.7 & $\mathrm{~mm}$ \\
Cavity length (Iris to iris) & 542.4 & $\mathrm{~mm}$ \\
Cavity diameter & 339.9 & $\mathrm{~mm}$ \\
Aperture diameter & 84.0 & $\mathrm{~mm}$ \\
Bar length & 350.3 & $\mathrm{~mm}$ \\
Bar inner height & 80.0 & $\mathrm{~mm}$ \\
Angle & 50.0 & $\mathrm{deg}$ \\
Deflecting voltage $\left(V_{t}{ }^{\mathrm{a}}\right)$ & 0.375 & $\mathrm{MV}$ \\
Peak electric field $\left(E_{p}{ }^{\mathrm{a}}\right)$ & 4.02 & $\mathrm{MV} / \mathrm{m}$ \\
Peak magnetic field $\left(B_{p}{ }^{\mathrm{a}}\right)$ & 7.06 & $\mathrm{mT}$ \\
$B_{p} / E_{p}$ & 1.76 & $\mathrm{mT} /(\mathrm{MV} / \mathrm{m})$ \\
Energy content $\left(U^{\mathrm{a}}\right)$ & 0.195 & $\mathrm{~J}$ \\
Geometrical factor $(G)$ & 140.9 & $\Omega$ \\
{$[R / Q]_{t}$} & 287.0 & $\Omega$ \\
$R_{t} R_{s}$ & $4.0 \times 10^{4}$ & $\Omega^{2}$ \\
\hline \hline
\end{tabular}

${ }^{\mathrm{a}}$ At $E_{t}=1 \mathrm{MV} / \mathrm{m}$. 


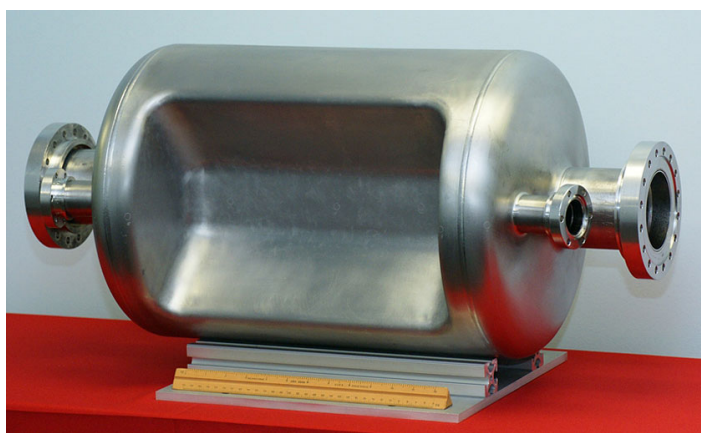

FIG. 4. Fabricated $400 \mathrm{MHz}$ rf-dipole cavity.

for additional diagnostics. The cavity was fabricated in four parts including the two end plates and the two halves of the center shell, using $3 \mathrm{~mm}$ thick $\mathrm{Nb}$ sheets with a residual resistivity ratio of 355-405. Each part was deep drawn using a set of dies with two pairs and electron beam welded [26]. The center shell was trimmed to obtain the design frequency at room temperature and then electron beam welded with the end plates. The beam ports and side ports are brazed with stainless steel conflat flanges. Following the final welding the cavity was leak tested. The final cavity is shown in Fig. 4. All the welding seams were scanned using the optical inspection system [28] at Jefferson Lab and no defects or irregularities were found.

The rf-dipole fundamental mode includes both on-axis transverse electric and magnetic fields. A bead pull method [29] was used to measure and evaluate the on-axis field components. The shift in resonant frequency due to field perturbation was measured using a Teflon spherical bead (dielectric bead) with a relative dielectric constant $\left(\varepsilon_{r}\right)$ of 2.05 and an aluminum spherical bead (metallic bead). The dielectric bead measures only the on-axis electric field. Since the transverse electric field component $\left(E_{x}\right)$ is the only on-axis electric field component this method measures the transverse electric field contribution to the net deflection. The metallic bead measures both on-axis electric and magnetic field components, in the case of the rf-dipole cavity $E_{x}$ and $H_{y}$ components. The perturbed fields for the dielectric and metallic beads were determined by

$$
\begin{gathered}
\frac{\Delta f}{f}=-\frac{\pi r^{3}}{U}\left[\varepsilon_{0} \frac{\varepsilon_{r}-1}{\varepsilon_{r}+2} E_{0}^{2}\right], \\
\frac{\Delta f}{f}=-\frac{\pi r^{3}}{U}\left[\varepsilon_{0} E_{0}^{2}-\frac{1}{2} \mu_{0} H_{0}^{2}\right] .
\end{gathered}
$$

The field perturbation measurements were obtained from the dielectric and metallic beads of diameters of 6.34 and $7.12 \mathrm{~mm}$, respectively. The measurements were compared with the simulations from CST MICROWAVE STUDIO [22]. The measurements are in complete agreement with the simulation data as shown in Fig. 5. The contribution to the deflecting voltage from the on-axis magnetic field $\left(H_{y}\right)$ is very small compared to that from the electric field $\left(E_{x}\right)$. The contribution from the on-axis magnetic field is the small perturbation at the entrance and exit of the cavity as seen in the measurements from the metallic bead shown in Fig. 5.

Surface treatment and careful preparation are important in obtaining a high performance superconducting rf cavity and overcoming the limiting factors such as field emission, quenches due to defects, and multipacting conditions [30,31]. The cavity was processed at Jefferson Lab in preparation for the rf testing following the standard cavity processing procedure [32]. The process removes the surface damage layer caused by sheet preparation and cavity fabrication. The cavity was chemically etched using the bulk buffered chemical polishing (BCP) process in order to remove the typical damaged layer of $120-150 \mu \mathrm{m}$. The BCP acid mixture consisted of $\mathrm{HF}: \mathrm{HNO}_{3}: \mathrm{H}_{2} \mathrm{PO}_{4}$ in 1:1:2 parts of $49 \%: 69.5 \%: 85 \%$ concentration each. However, the cavity was processed at a low etch rate of $1.8 \mu \mathrm{m} / \mathrm{min}$ due to a contamination of the acid mixture by glycol. The cavity was processed by a temperature-controlled acid mixture at $8^{\circ} \mathrm{C}$ in order to minimize the absorption of
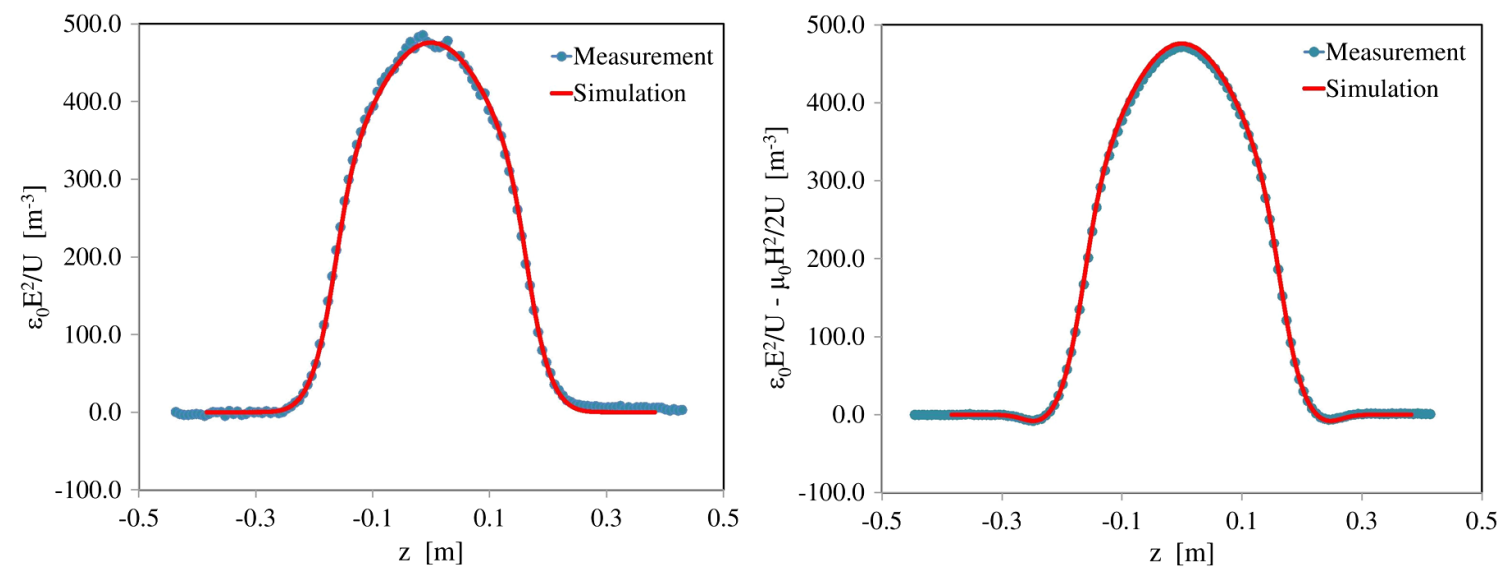

FIG. 5. Bead pull measurements from the dielectric (left) and metallic (right) spherical beads. 


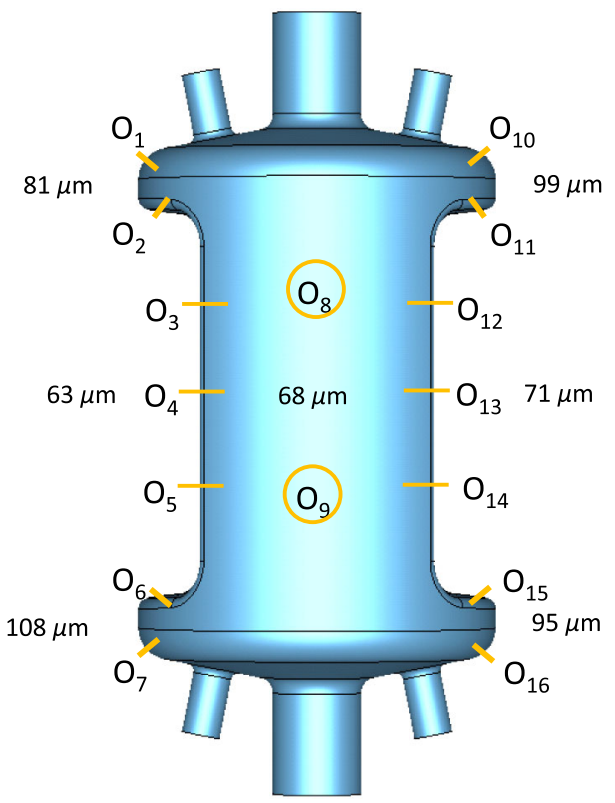

FIG. 6. Average surface removal measured with an ultrasonic probe from the bulk BCP process.

hydrogen into the surface in a closed vertical cabinet. The acid mixture was inserted from the bottom three ports and removed from the top three ports of the cavity, mounted vertically, using a manifold and circulated through the cavity in one direction for 17 minutes for a nominal removal of $30 \mu \mathrm{m}$. For each iteration of $30 \mu \mathrm{m}$ removal, the cavity was overturned to obtain a more uniform removal. The process was repeated 4 times aiming a total nominal removal of $120 \mu \mathrm{m}$. The geometry of the rf-dipole cavity does not allow a uniform acid flow in the cavity, and therefore leads to a nonuniform removal on the inner surface. Figure 6 shows the average removal measured with an ultrasonic probe at different locations on the cavity. The measurements were obtained from the Panametrics 25DL-Plus ultrasonic precision thickness gage with a resolution of $1 \mu \mathrm{m}$ [33]. The average removal was $81 \mu \mathrm{m}$; however at the center of the cavity the removal was an average of $67 \mu \mathrm{m}$ while at the top and bottom of the cavity the average removal was $95 \mu \mathrm{m}$. From repeated measurements we estimate that the amounts removed are accurate to $\pm 10 \mu \mathrm{m}$.

Following the bulk chemistry, the cavity was heat treated in a high-vacuum furnace at $600^{\circ} \mathrm{C}$ for a duration of 10 hours for degassing of the hydrogen that was absorbed into the surface during the bulk BCP process [34]. Figure 7 shows the decrease of partial pressure of hydrogen and other elements during the heat treatment. The heating process was initiated after the furnace reached a pressure of $10^{-6}$ torr. From experience a good level of degassing is achieved with a hydrogen partial pressure below $10^{-6}$ torr at the end of the process [35]. The cavity was etched again in a light $\mathrm{BCP}$ process to remove $\sim 10 \mu \mathrm{m}$ to eliminate the contamination due to the high-temperature heat treatment.

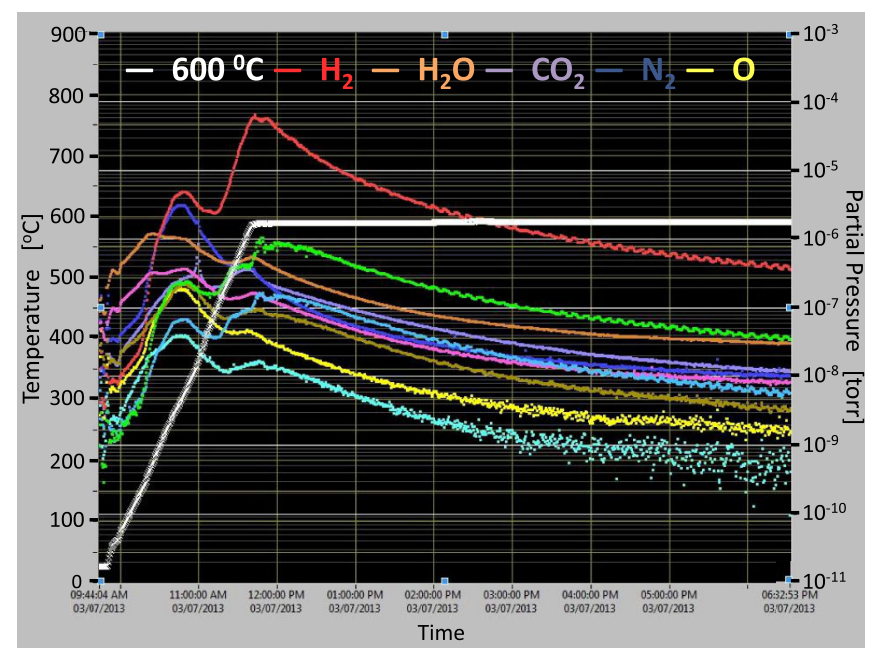

FIG. 7. Furnace temperature and $\mathrm{H}_{2}$ partial pressure level during high-vacuum heat treatment.

Finally, the cavity was high-pressure rinsed in three passes with ultrapure water for 75 minutes at a pressure of $1250 \mathrm{psi}$, prior to assembly. The cavity was assembled in a class 10 clean room with relief valves, fixed input coupler at the bottom and pickup probe at the top of the cavity as shown

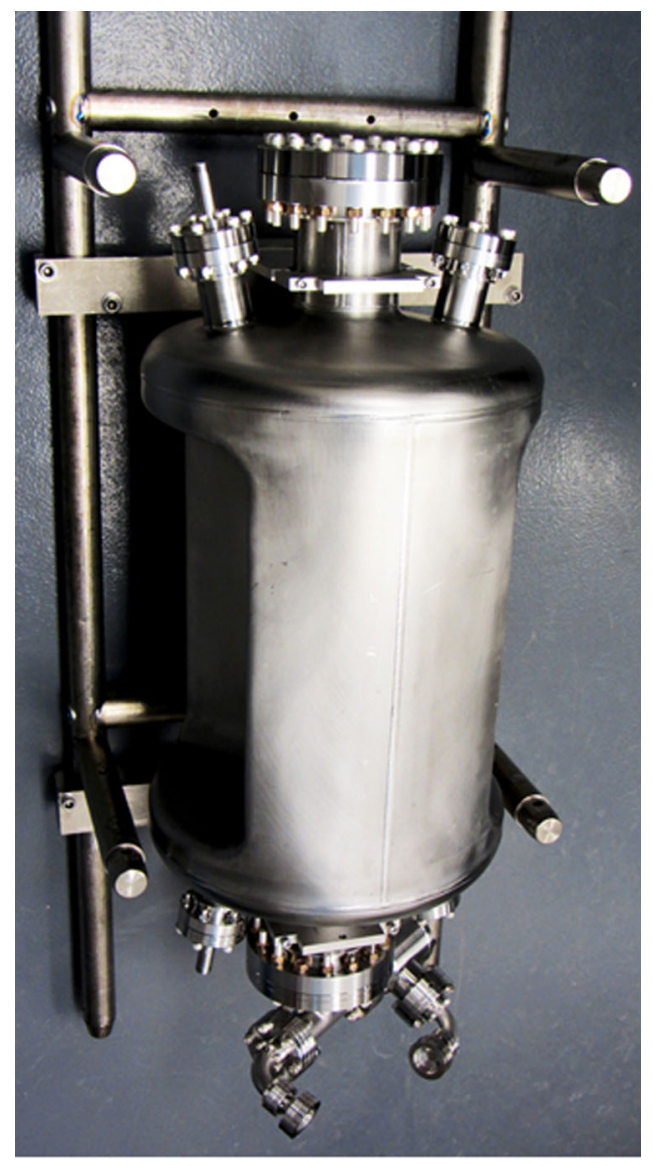

FIG. 8. Assembled cavity prior to test with fixed input coupler at the bottom and pickup probe at the top. 
in Fig. 8 and mounted into a test stand for vertical testing. We omitted the mild baking at $\sim 120^{\circ} \mathrm{C}$ which is often used.

\section{RADIO-FREQUENCY TESTING}

The $400 \mathrm{MHz}$ rf-dipole cavity was tested in cw operation using a $500 \mathrm{~W}$ rf amplifier at both low power and high power. The input coupling was fixed at a $Q_{\text {ext }}=3.0 \times 10^{9}$ and was slightly overcoupled at $2.0 \mathrm{~K}$. A series of vertical rf tests were performed on the cavity at cryogenic temperatures of 4.2 and $2.0 \mathrm{~K}$ in the vertical test facility at Jefferson Lab.

\section{A. Multipacting}

Multipacting is a complex phenomenon that may limit the performance of any rf cavity. Hard multipacting levels can be eliminated by modifying the geometry at the design stage. However, soft multipacting barriers may exist in an rf cavity and may be a limiting factor depending on the conditions of the inner surface. The multipacting levels were analyzed for the $400 \mathrm{MHz}$ rf-dipole cavity using the
TRACK3P package from the SLAC ACE3P code suite [36] for an impact energy range of $20-2000 \mathrm{eV}$, which is the critical level in secondary emission for $\mathrm{Nb}[31,37]$. Because of the similarity to a parallel platelike geometry multipacting conditions may exist in the rf-dipole geometry [38]. The impact energy of the resonant particles as a function of the transverse voltage, shown in Fig. 9, suggests multipacting levels with a secondary emission yield greater than 1.0, for a period of $50 \mathrm{rf}$ cycles. Most of the order 1 multipacting levels at higher transverse voltages disappear at operation with higher rf cycles. As shown in Fig. 10, the resonant particles with the critical impact energies lie primarily on the end plates of the rf-dipole cavity where the multipacting is of order 1 [39].

The cavity was initially tested at $2.0 \mathrm{~K}$ followed by a test at $4.2 \mathrm{~K}$ and another test at $2.0 \mathrm{~K}$. In the first $2.0 \mathrm{~K}$ high power rf test a multipacting barrier was observed at very low fields. After a few minutes the input power was increased, the multipacting level disappeared, and the transverse voltage jumped to about $2.5 \mathrm{MV}$. As shown in Fig. 9, both barriers were easily processed with increasing

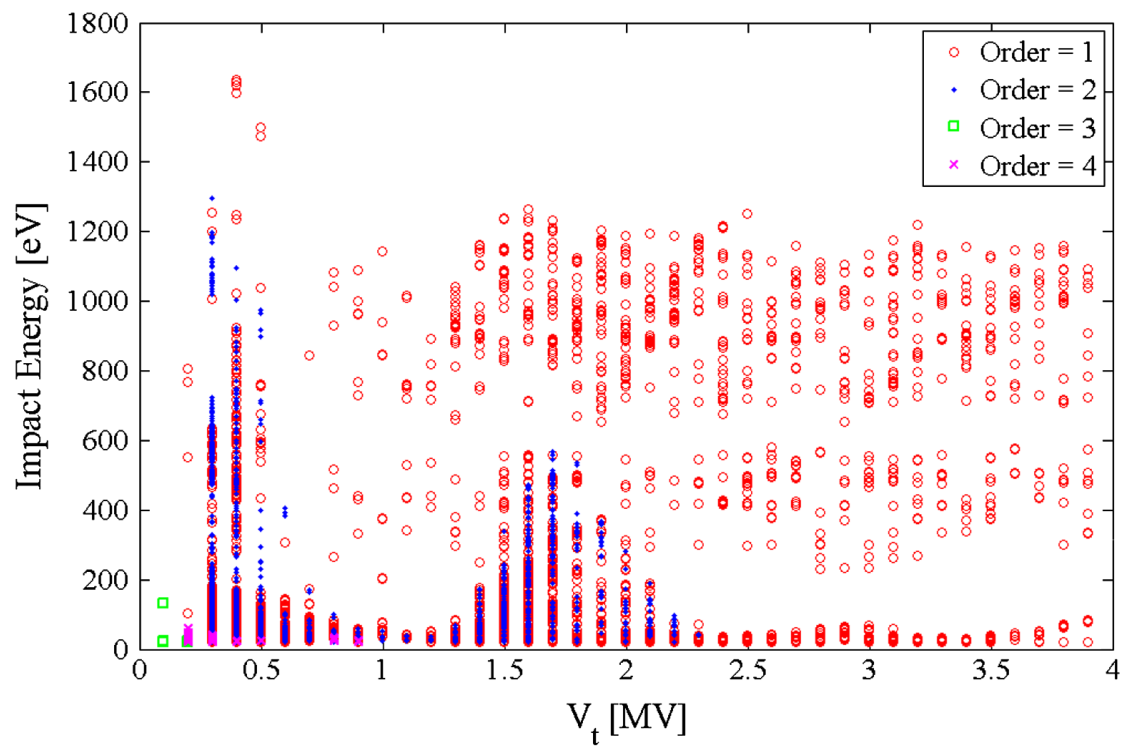

FIG. 9. Electron impact energy in the $400 \mathrm{MHz}$ rf-dipole cavity with varying transverse voltage.
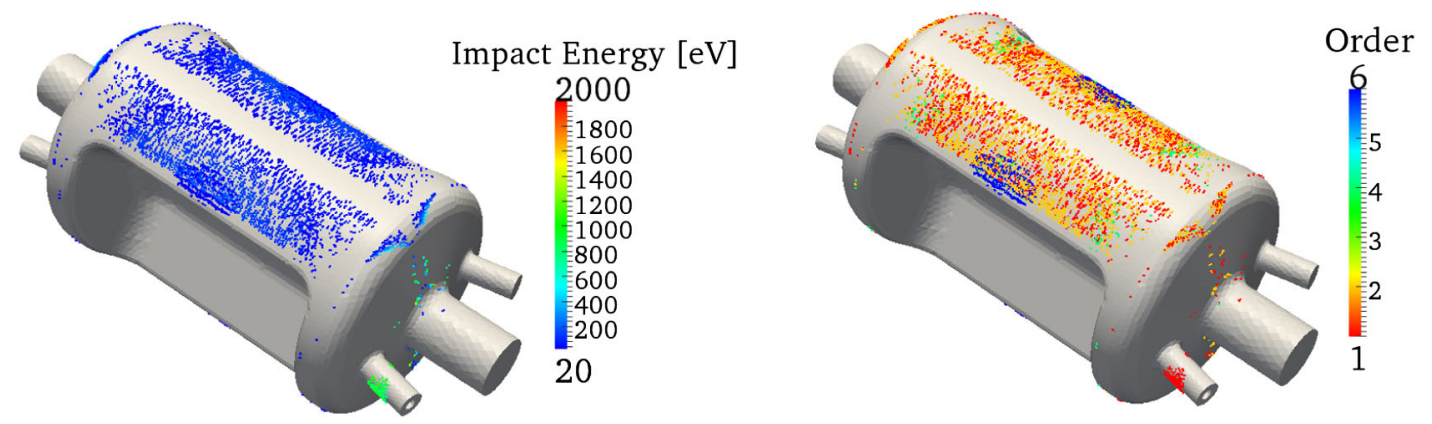

FIG. 10. Position of the resonant particles on the rf-dipole cavity with corresponding impact energy (left) and multipacting order (right). 


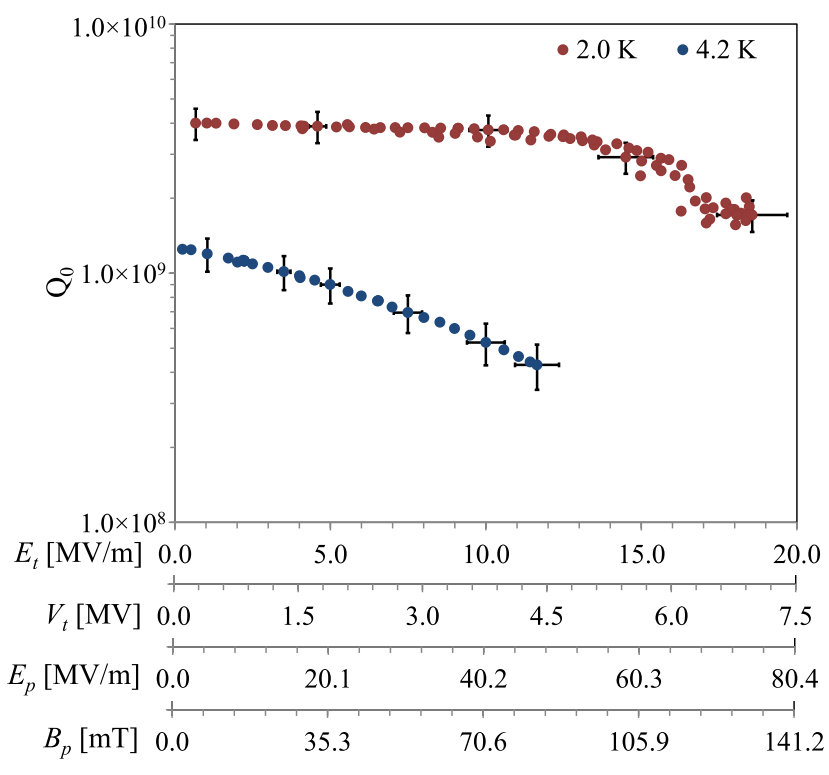

FIG. 11. Quality factor at 4.2 and $2.0 \mathrm{~K} \mathrm{rf}$ tests.

input power, and were shown to be soft multipacting barriers. The input power was then decreased down to $1 \mathrm{MV}$ in small steps and no multipacting levels were observed. Further multipacting levels were not observed during the remainder of the $2.0 \mathrm{~K}$ test or on the following 4.2 and $2.0 \mathrm{~K}$ tests. This observation is consistent with what was expected from the simulations.

\section{B. Radio-frequency measurements}

The performance of the rf-dipole cavity was obtained by measuring the unloaded quality factor $\left(Q_{0}\right)$ as a function of the transverse voltage. Figure 11 shows the measured unloaded quality factor as functions of the transverse electric field $\left(E_{t}\right)$, transverse voltage $\left(V_{t}\right)$, peak surface electric field $\left(E_{p}\right)$, and peak surface magnetic field $\left(B_{p}\right)$.

The $Q$ curve at $4.2 \mathrm{~K}$ shows a distinctive slope while it is relatively flat at $2.0 \mathrm{~K}$. This is a fairly common feature that has been often observed in low-frequency superconducting cavities $[40,41]$. Its origin is still poorly understood but possibly related to the heat transfer between $\mathrm{Nb}$ and liquid He. During the $4.2 \mathrm{~K}$ tests, the cavity achieved a transverse voltage of $4.35 \mathrm{MV}$ that corresponds to a transverse deflecting field of $11.6 \mathrm{MV} / \mathrm{m}$ and was limited by the $\mathrm{rf}$ power available. The cavity was dissipating over $150 \mathrm{~W}$ at $11.6 \mathrm{MV} / \mathrm{m}$.

At $2.0 \mathrm{~K}$ the $Q$ curve was flat with increasing gradient. The cavity achieved a transverse voltage of 7.0 MV where a quench was observed. The $Q$ curve was flat until $5.0 \mathrm{MV}$ and dropped possibly due to field emission. Figure 12 shows the radiation produced by field emission during the 4.2 and $2.0 \mathrm{~K}$ high power rf tests and measured at the top of the Dewar. Since the cavity was sealed and not actively pumped there was no opportunity to do He processing [42]. During the $2.0 \mathrm{~K}$ test the cavity reached cw

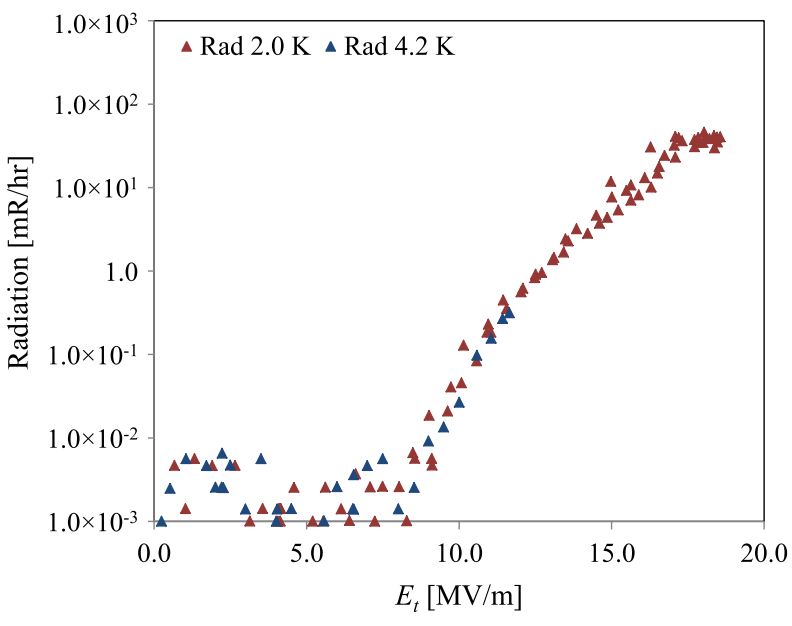

FIG. 12. Field emission at 4.2 and $2.0 \mathrm{~K}$ rf tests.

peak surface fields of $75 \mathrm{MV} / \mathrm{m}$ and $131 \mathrm{mT}$. The achieved $\mathrm{cw}$ voltage of 7.0 MV is twice the design voltage of $3.4 \mathrm{MV}$ for the crabbing cavities for the proposed LHC high luminosity upgrade [27].

\section{Lorentz force detuning}

The Lorentz force detuning is an effect where the cavity is deformed by the radiation pressure [43]. The magnetic field applies pressure and deforms the surface outward, while deformation due to electric field is inward. The change in cavity resonant frequency due to Lorentz force detuning was measured as shown in Fig. 13. At both 4.2 and $2.0 \mathrm{~K}$ the Lorentz coefficients were calculated to be $k_{L}=-122 \mathrm{~Hz} /(\mathrm{MV} / \mathrm{m})^{2}$. The measured coefficient is relatively high due to large flat surfaces in the rf-dipole cavity, and can be reduced by adding stiffeners at appropriate locations.

\section{Pressure sensitivity}

The mechanical analysis carried out using the structural mechanical tool in ANSYS [44] shows the sensitivity of

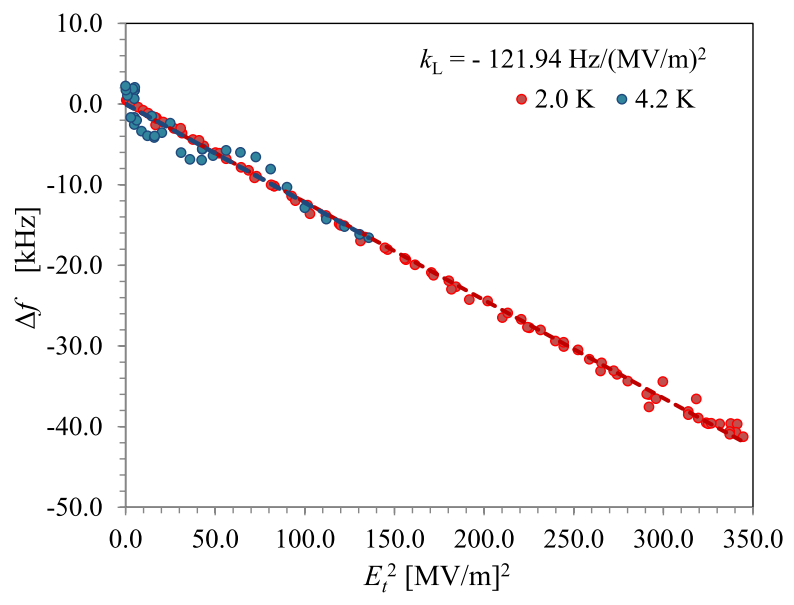

FIG. 13. Lorentz force detuning at 4.2 and $2.0 \mathrm{~K}$ rf tests. 

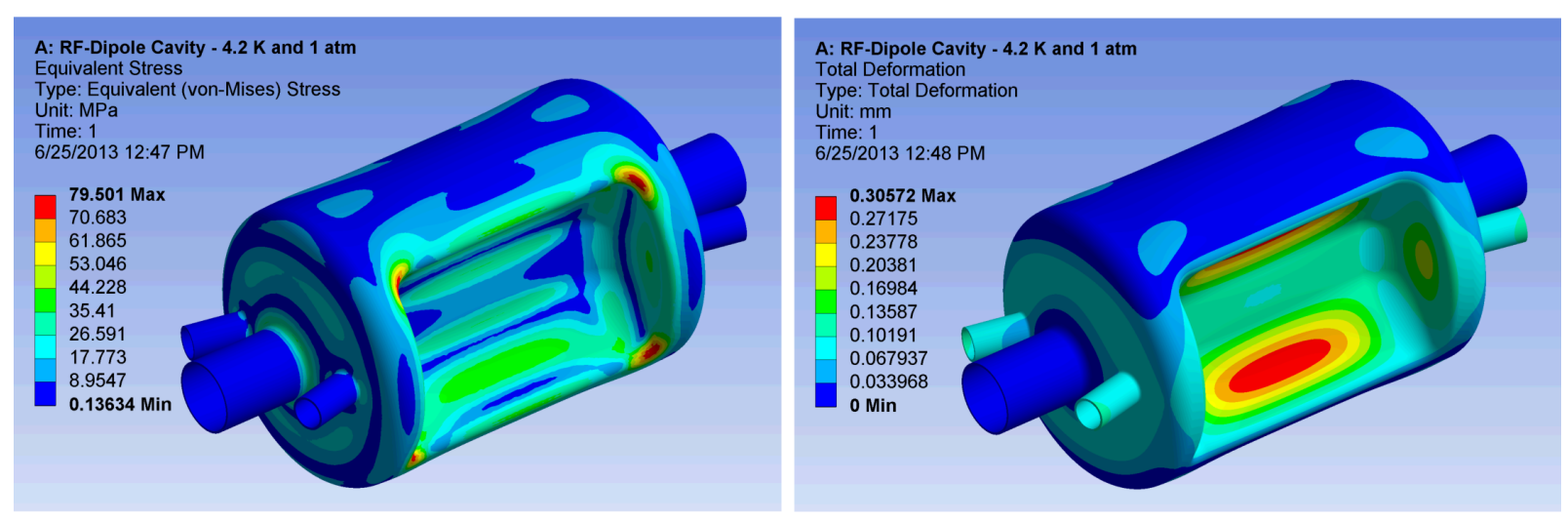

FIG. 14. Stress (left) and deformation (right) due to pressure.

the cavity at operational conditions for a cavity with $3 \mathrm{~mm}$ thickness and no stiffening. At $4.2 \mathrm{~K}$ with an external pressure of $1 \mathrm{~atm}$, the rf-dipole cavity experiences stresses of $79 \mathrm{MPa}$, at the edges of the trapezoidal-shaped loading elements as shown in Fig. 14 which is within the acceptable limits considering the operational conditions. The beam aperture area of the cavity is deformed inward resulting in an outward deformation of the sides of the trapezoidal-shaped loading elements as shown in Fig. 14, which shows the highest sensitivity with a maximum deformation of $0.31 \mathrm{~mm}$.

The rf-dipole cavity sensitivity to the pressure was measured in a low power if test in $\mathrm{cw}$ operation during the cooldown of the cavity from 4.2 to $2.0 \mathrm{~K}$. The cavity showed a pressure sensitivity of $0.5 \mathrm{kHz} /$ torr as shown in Fig. 15. Again this can be reduced by including stiffeners at appropriate locations.

\section{Surface resistance and power dissipation}

The effective surface resistance $\left(R_{S}\right)$ was calculated by $R_{s}=G / Q_{0}$ using the unloaded quality factor measured during the cavity cooling down process from 4.2 to $2.0 \mathrm{~K}$ and the geometrical factor $(G)$ of the $400 \mathrm{MHz}$ rf-dipole

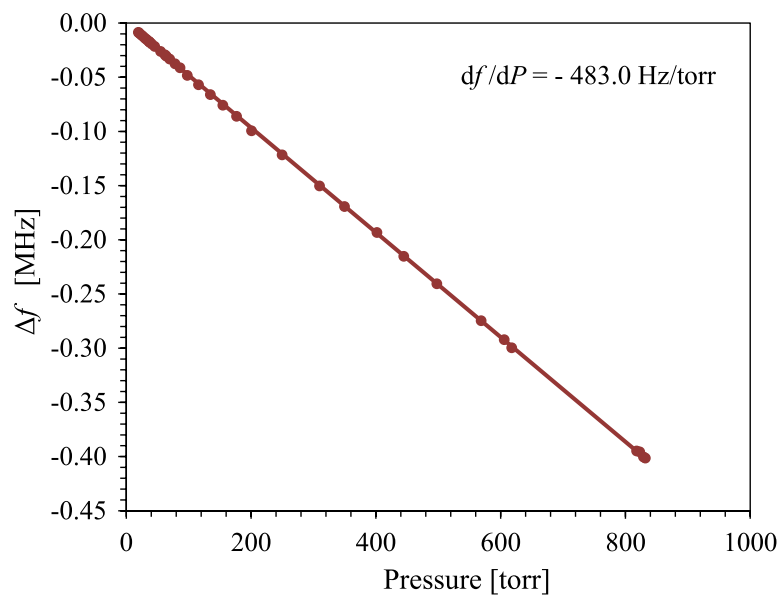

FIG. 15. Pressure sensitivity of the rf-dipole cavity. cavity given in Table I. The measurements were taken at a field range of $0.5-0.65 \mathrm{MV} / \mathrm{m}$ that corresponds to $0.2-0.25 \mathrm{MV}$. The estimated residual surface resistance of $34 \mathrm{n} \Omega$, shown in Fig. 16, was determined by fitting the measured data with the BCS theory [45]. The best fit to our data was

$$
R_{s}[\mathrm{n} \Omega]=\frac{2.6 \times 10^{4}}{T[\mathrm{~K}]} \exp \left[-\frac{18.67}{T[\mathrm{~K}]}\right]+33.9 .
$$

The measured losses were higher and $Q_{0}$ lower than expected due to the high residual surface resistance. Therefore careful analysis was done to identify the accountable surface losses, and it was found that surface losses at the beam port stainless flanges were significant. During the tests the beam ports were blanked with stainless steel flanges and these were found to give rise to nonnegligible losses as shown in Table II. Losses at the blanked side ports were insignificant. Losses calculated at the beam ports give an unloaded quality factor $\left(Q_{0}\right)$ of $3.8 \times 10^{9}$ which agrees with the measured $Q_{0}$ of $4.0 \times 10^{9}$ at $2.0 \mathrm{~K}$. The expected $\mathrm{BCS}$ resistance for $\mathrm{Nb}$ at $400 \mathrm{MHz}$ is $R_{\mathrm{BCS}}=1.3 \mathrm{n} \Omega$ at $2.0 \mathrm{~K}$ and $R_{\mathrm{BCS}}=70.0 \mathrm{n} \Omega$ at $4.2 \mathrm{~K}$

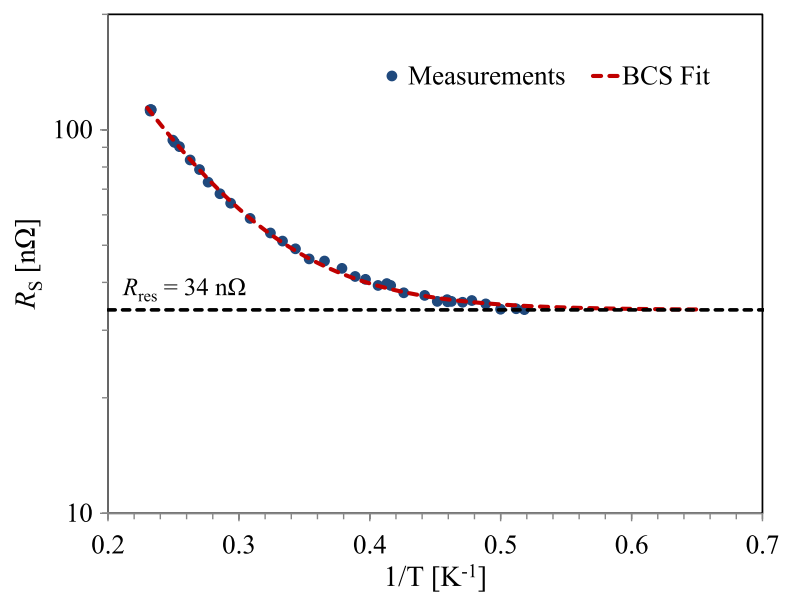

FIG. 16. Effective surface resistance during the cavity cooldown from 4.2 to $2.0 \mathrm{~K}$. 
TABLE II. Port losses at beam and coupler ports.

\begin{tabular}{lcc}
\hline \hline Parameter & Value & Units \\
\hline $\begin{array}{l}\text { Surface resistance of stainless steel } \\
\text { Beam ports }\end{array}$ & 0.033 & $\Omega$ \\
Power loss at beam ports $^{\mathrm{a}}$ & 0.69 & $\mathrm{~W}$ \\
$Q_{0}$ due to the power loss at beam ports & $3.8 \times 10^{9}$ & \\
Side ports & & \\
Power loss at side ports & \\
$Q_{0}$ due to the power loss at side ports & $3.3 \times 10^{11}$ & $\mathrm{~W}$ \\
\hline \hline
\end{tabular}

${ }^{\mathrm{a}}$ At $U=1.0 \mathrm{~J}$.

[45]. Therefore the losses at the beam ports are dominant at $2.0 \mathrm{~K}$, however at $4.2 \mathrm{~K}$ the BCS losses are higher and do not dominate the losses at the beam ports.

\section{CONCLUSION}

The first rf test of the proof-of-principle $400 \mathrm{MHz}$ rf-dipole cavity has demonstrated excellent rf properties at both 4.2 and $2.0 \mathrm{~K}$. The multipacting levels were easily processed. High surface electric and magnetic fields were achieved and high deflecting voltages were demonstrated in $\mathrm{cw}$ operation. The relatively high residual surface resistance measured at $2.0 \mathrm{~K}$ was consistent with the power dissipated at the stainless steel flanges blanking the beam line ports. The rf test results obtained by the $400 \mathrm{MHz}$ proof-of-principle rf-dipole cavity open up possibilities of using these rf structures in future deflecting and crabbing applications.

\section{ACKNOWLEDGMENTS}

We want to acknowledge the help we have received from the Jefferson Lab SRF Institute for the processing of the cavity, and preparation for and conducting of the tests. We want to give special thanks to HyeKyoung Park, Peter Kneisel, Tom Powers, and Kirk Davis of Jefferson Lab. This work was partially supported by the U.S. Department of Energy through the U.S. LHC Accelerator Research Program (LARP), by the EU FP7 HiLumi LHC-Grant Agreement No. 284404, and by the U.S. DOE HEP SBIR/STTR program through Niowave Inc., Lansing, MI. This research used resources of the National Energy Research Scientific Computing Center, which is supported by the Office of Science of the U.S. Department of Energy under Contract No. DE-AC02-05CH11231.

[1] P. R. Phillips, Rev. Sci. Instrum. 32, 13 (1961).

[2] M. Bell, P. Bramham, and B.W. Montague, Nature (London) 198, 277 (1963).

[3] O. H. Altenmueller, R. R. Larsen, and G. A. Loew, Rev. Sci. Instrum. 35, 438 (1964).

[4] H. Hahn and H. J. Halama, Rev. Sci. Instrum. 36, 1788 (1965).
[5] H. Hahn, Rev. Sci. Instrum. 34, 1094 (1963).

[6] A. Citron, G. Dammertz, M. Grundner, L. Husson, R. Lehm, H. Lengeler, D. E. Plane, and G. Winkler, Nucl. Instrum. Methods 155, 93 (1978).

[7] C. W. Leemann and C. G. Yao, in Proceedings of the 1990 Linear Accelerator Conference, Albuquerque, New Mexico (Los Alamos Report No. LA-12004-C, 1991), p. 232 [http://accelconf.web.cern.ch/accelconf/190/papers/ mo465.pdf].

[8] Y. Senichev, O. Belyaev, W. Bräutigam, Y. Budanov, R. Maier, V. Stepanov, V. Teplyakov, A. Zherebtsov, and I. Zvonarev, Phys. Rev. ST Accel. Beams 9, 012001 (2006).

[9] R. B. Palmer, SLAC Technical Report No. SLAC-PUB4707, 1988 [http://www.slac.stanford.edu/cgi-wrap/getdoc/ slac-pub-4707.pdf].

[10] K. Oide and K. Yokoya, Phys. Rev. A 40, 315 (1989).

[11] K. Hosoyama, K. Hara, A. Kabe, Y. Kojima, Y. Morita, H. Nakai, L. S. Peng, K. Ohkubo, H. Hatori, and M. Inoue, in Proceedings of the 1998 Asian Particle Accelerator Conference, Tsukuba, Japan (KEK Proceedings 98-10, 1998), p. 828 [http://accelconf.web.cern.ch/accelconf/a98/ APAC98/6D064.PDF].

[12] T. Abe et al., in Proceedings of the 2007 Particle Accelerator Conference, Albuquerque, New Mexico, USA (IEEE, New York, 2007), p. 27 [http://accelconf.web .cern.ch/AccelConf/p07/PAPERS/MOZAKI01.PDF].

[13] R. Calaga, in Proceedings of the 2011 Conference on $R F$ Superconductivity, Chicago, Illinois (ANL, Chicago, Illinois, 2011), p. 988 [http://accelconf.web.cern.ch/ accelconf/SRF2011/papers/friob05.pdf].

[14] Z. Li, L. Xiao, C. Ng, and T. Markiewicz, in Proceedings of the 2010 International Particle Accelerator Conference, Kyoto, Japan (IPAC'10 OC/ACFA, Kyoto, Japan, 2010), p. 504 [http://accelconf.web.cern.ch/accelconf/IPAC10/ papers/mopec022.pdf].

[15] J. R. Delayen and H. Wang, Phys. Rev. ST Accel. Beams 12, 062002 (2009).

[16] B. Hall, G. Burt, C. Lingwood, R. Rimmer, and H. Wang, in Proceedings of the 2010 International Particle Accelerator Conference, Kyoto, Japan (Ref. [14]), p. 3001 [http://accelconf.web.cern.ch/accelconf/IPAC10/ papers/wepec049.pdf].

[17] J. R. Delayen, in Proceedings of the 2011 Conference on RF Superconductivity, Chicago, Illinois (Ref. [13]), p. 631 [http://accelconf.web.cern.ch/AccelConf/SRF2011/ papers/thioa03.pdf].

[18] I. Ben-Zvi, in Proceedings of the 2011 Conference on RF Superconductivity, Chicago, Illinois (Ref. [13]), p. 637 [http://accelconf.web.cern.ch/accelconf/SRF2011/papers/ thioa04.pdf].

[19] S. U. De Silva, in Proceedings of the 2012 Linear Accelerator Conference, Tel-Aviv, Israel (JACoW, 2012), p. 95 [http:// accelconf.web.cern.ch/AccelConf/LINAC2012/papers/ supb039.pdf].

[20] S. U. De Silva and J.R. Delayen, Phys. Rev. ST Accel. Beams 16, 012004 (2013).

[21] J. R. Delayen and S. U. De Silva, in Proceedings of the 2011 Conference on RF Superconductivity, Chicago, Illinois (Ref. [13]), p. 219 [http://accelconf.web.cern.ch/ accelconf/SRF2011/papers/mopo053.pdf]. 
[22] Microwave Studio, CST GmbH, Darmstadt, Germany (2012) [http://www.cst.com].

[23] W. K. H. Panofsky and W. A. Wenzel, Rev. Sci. Instrum. 27, 967 (1956).

[24] M.J. Browman, in Proceedings of the 1993 Particle Accelerator Conference, Washington, D.C. (IEEE, New York, 1993), p. 800 [http://accelconf.web.cern.ch/ accelconf/p93/PDF/PAC1993_0800.PDF].

[25] S. U. De Silva and J.R. Delayen, in Proceedings of the 2011 Conference on RF Superconductivity, Chicago, Illinois (Ref. [13]), p. 135 [http://accelconf.web.cern.ch/ accelconf/SRF2011/papers/mopo027.pdf].

[26] D. Gorelov, T. L. Grimm, S. U. De Silva, and J.R. Delayen, in Proceedings of the 2012 International Particle Accelerator Conference, New Orleans, USA (IEEE, Piscataway, NJ, 2012), p. 2411 [http://accelconf .web.cern.ch/AccelConf/IPAC2012/papers/weppc085.pdf].

[27] P. Baudrenghien, K. Brodzinski, R. Calaga, O. Capatina, E. Jensen, A. Macpherson, E. Montesinos, and V. Parma, CERN Technical Report No. CERN-ACC-NOTE-2013003, 2013 [http://cds.cern.ch/record/1520896/files/CERNACC-NOTE-2013-003.pdf]

[28] R.L. Geng, in Proceedings of the 2011 Conference on RF Superconductivity, Chicago, Illinois (Ref. [13]), p. 798 [http://accelconf.web.cern.ch/AccelConf/SRF2011/ papers/thpo036.pdf].

[29] L. C. Maier and J. C. Slater, J. Appl. Phys. 23, 68 (1952).

[30] J. Knobloch, IEEE Trans. Appl. Supercond. 9, 1016 (1999).

[31] H. Padamsee and A. Joshi, J. Appl. Phys. 50, 1112 (1979).

[32] P. Kneisel, Nucl. Instrum. Methods 557, 250 (2006).

[33] "Panametrics 25DL-Plus Ultrasonic Precision Thickness Gage" [http://www.olympus-ims.com/en/25dl-plus].

[34] B. Bonin and R. Röth, Part. Accel. 40, 59 (1992) [http:// cds.cern.ch/record/1055117/files/p59.pdf].
[35] G. Ciovati, G. Myneni, F. Stevie, P. Maheshwari, and D. Griffis, Phys. Rev. ST Accel. Beams 13, 022002 (2010).

[36] K. Ko, A. Candel, L. Ge, A. Kabel, R. Lee, Z. Li, C. Ng, V. Rawat, G. Schussman, and L. Xiao, in Proceedings of the 25th International Linear Accelerator Conference LINAC10, Tsukuba, Japan (KEK, Tsukuba, Japan, 2010), p. 1028 [http://accelconf.web.cern.ch/accelconf/ LINAC2010/papers/fr101.pdf].

[37] R. Calder, G. Dominichini, and N. Hilleret, Nucl. Instrum. Methods 13, 631 (1986).

[38] S. U. De Silva and J.R. Delayen, in Proceedings of the 2011 Particle Accelerator Conference, NY, USA (IEEE, New York, 2011), p. 1018 [http://accelconf.web.cern.ch/ accelconf/PAC2011/papers/tup098.pdf].

[39] S. U. De Silva, A. Castilla, and J.R. Delayen, in Proceedings of the 2013 International Particle Accelerator Conference, Shanghai, China (JACoW, 2013), p. 2483 [http://accelconf.web.cern.ch/AccelConf/ IPAC2013/papers/wepwo080.pdf].

[40] J. R. Delayen, in Proceedings of the 25th International Linear Accelerator Conference LINAC10, Tsukuba, Japan (Ref. [36]), p. 377 [http://accelconf.web.cern.ch/ AccelConf/LINAC2010/papers/tu302.pdf].

[41] M. Kelly, in Proceedings of the 2007 Conference on RF Superconductivity, Beijing, China (Peking University, Beijing, China, 2007), p. 44 [http://accelconf.web.cern.ch/ AccelConf/srf2007/PAPERS/WE302.pdf].

[42] H. A. Schwettman, J.P. Turneaure, and R.F. Waites, J. Appl. Phys. 45, 914 (1974).

[43] J. C. Slater, Rev. Mod. Phys. 18, 441 (1946).

[44] ANSYS ${ }^{\circledR}$ Academic Research, Release 13.0, Structural Mechanics Analysis, ANSYS, Inc.(2010) [http://www .ansys.com].

[45] J. Halbritter, Z. Phys. 266, 209 (1974). 